\title{
ACCOUNTING, MANAGEMENT CONTROL AND THE FINANCIAL FUNCTION IN THE MISSION OF THE FIRM
}

\author{
Josep M. Rosanas
}




\title{
ACCOUNTING, MANAGEMENT CONTROL AND THE FINANCIAL FUNCTION IN THE MISSION OF THE FIRM
}

\author{
Josep M. Rosanas ${ }^{1}$
}

\begin{abstract}
Accounting systems are an essential tool for providing information for decision making intended for the survival of the firm in the long run, which will benefit the different stakeholders of the firm (if managed properly) and society in general. Of course, the financial function and the financial institutions have an important role to fulfill from a social welfare point of view as well: that of obtaining resources at a reasonable cost and using them efficiently. But financial management, instead of being a tool, can be converted into the main objective of the firm, and accounting in this context (heavily influenced by finance) may be misused for this purpose, mainly in the short run. Often, this leads to behaviors that become unethical. The functions that accounting and finance should perform, understood only as tools to achieve higher objectives (essentially, an operational and sound mission for the firm), are taken to be the objectives to be pursued, to the detriment of the firm's mission itself. Typically, when this is done, this type of inversion of values encourages unethical behavior. This paper is intended to show how this is possible and why, and what the possible ways to keep this from happening are.
\end{abstract}

Keywords: Ethics of accounting; Ethics of finance; Indicators; Individual motives; Management control; Mission

\footnotetext{
${ }^{1}$ Professor Accounting and Control, University of Navarra.
} 


\section{ACCOUNTING, MANAGEMENT CONTROL AND THE FINANCIAL FUNCTION IN THE MISSION OF THE FIRM}

Accounting and management control on the one hand and finance on the other are important functions for the management of any firm or any organization in general. They both have an important role to fulfill and this role can be performed in a professional (and, of course, ethical) way. Accounting systems are an essential tool for providing information for decision making and trying to make sure that the firm can survive financially in the long run, which will benefit the different stakeholders of the firm (if managed properly) and society in general. Of course, the financial function and the financial institutions have an important role to fulfill from a social welfare point of view as well: that of obtaining resources at a reasonable cost and using them efficiently. But financial management, instead of being a tool, can be converted into the main objective of the firm, and accounting in this context (heavily influenced by finance) may be misused for this purpose, mainly in the short run. Often, this leads to behaviors that become unethical. The functions that accounting and finance should perform, understood only as tools to achieve higher objectives (essentially, an operational and sound mission for the firm), are taken to be the objectives to be pursued, to the detriment of the firm's mission itself. Typically, when this is done, this type of inversion of values encourages unethical behavior. This paper is intended to show how this is possible and why, and what the possible ways to keep this from happening are.

I will proceed as follows. First, I will review in some depth the essential, standard microeconomics concepts that may lead to this inversion of values. Second, I'll provide an interpretation of these concepts that lead to the idea of the mission as the real objective of the firm. Third, I'll briefly discuss some of the reasons for management malpractice that often leads to unethical behavior and I'll illustrate them with some examples. Finally, I will suggest a way of managing that takes into account the short-term objectives that can be quantified as necessary indicators that have to meet some minimum conditions for survival, but that is geared towards the concept of mission, that necessarily requires going beyond the financial and even the nonfinancial quantifiable variables, paying careful attention to the nonquantifiable variables that are related to the mission and, therefore, to society's welfare.

\section{The Theory of the Firm}

Firms are obviously today a crucial part of the economic world. In a sizable and structured form, they began with the industrial revolution of the 18th century, when the development of technology made it possible to produce different goods in considerable amounts, and the firm became the basic tool to achieve that purpose. Precisely because of that, firms were seen as a way to make a profit by the owners; and that possibility was clearly a major motive that induced entrepreneurs to start firms. 
Theory, as has always happened in the history of any science (Christenson 1976), lagged behind. About the time of the industrial revolution, modern economics started with the work of Adam Smith, intended to show the advantages of free trade and how an economic system based on free initiative was much better than one guided by the principles of accumulating gold and preventing people from spending it outside one's own nation. For this purpose, Smith tried to show how businessmen would do whatever is good for consumers not because of their concern for them, but because of their own self-interest: what later on was called "the invisible hand." In his work, the analysis of the firm is minimal (if there is any!). Its role is reduced to profit being the motive for the automatic regulation of the economic system. It wasn't until the late 19th century when, in the context of the "general equilibrium" (the formalized notion of the "invisible hand"), firms were assumed to maximize profit, with perfect knowledge of the production possibilities and of the prices of inputs and outputs, with unbounded rationality and without any internal conflict between the different people acting in the organization. Walras and other classical economists of the 19th century (Jevons, Menger, Edgeworth, etc.) provided mathematical formulations of these principles, which in the 20th century were formalized in a stricter and more rigorous way by Hicks and Samuelson. But the "theory of the firm" implicit in these solid microeconomic formulations was still reduced to an abstract entity that behaved along the lines just enunciated.

To be sure, at about the same time Hicks and Samuelson were refining the classical, standard approach, there were other economists working in a different direction that would explain important aspects of the firm as an entity that includes human beings and decision making. Ronald Coase (1937) started the approach that in the 1970s and 1980s was called "transaction cost economics" and was pursued mainly by Williamson (1985), which would explain the existence of the firm, as well as its size and boundaries, and also the extent to which markets and organizations shared the coordination of human activity, on the basis of whether a specific transaction is less costly in a market arrangement or taken hierarchically within an organization. Berle and Means (1932), in another classical work, showed how there could be a conflict of interests between owners and managers in deciding the actions to be taken by the firm, and therefore firms could possibly be run in the interests of their managers and not of their owners; and Irving Fisher (1930) proved an important "separation theorem" (under the classical assumptions of unbounded rationality and perfectly competitive markets) that showed that production decisions could be made independently of the owners' utility functions.

And also, in parallel (but independently), management theory began. After some initial ideas in the 19th century, Frederick Taylor developed what he called "scientific management," a set of techniques to study what manual workers did so that they could do it more efficiently, earning better salaries and producing bigger earnings for the firm. These were the three elements of Taylorism: efficiency, incentives and increased profits. But Taylorism did not provide any theory of the firm on which we could base management, in spite of the word "scientific"; it was only an effort to "scientifically" improve the mechanical work of people in manufacturing firms, based on observation and some knowledge of mechanics and of physiology.

Immediately, though, other lines of thought (perhaps less successful in the short run but much more solid conceptually and more influential in the long run) began to develop. Fayol in France established the first treatise of what was later to be called "general management" and Mary Parker Follet used the expression "scientific management," which had become so successful, to start the development of a science of cooperation (Follet 1925) that was substantially different from that of Taylor in both its objectives and its methods even though it used the same expression. But what she was able to elaborate was only very partial analyses of very specific problems (e.g., "The Giving of Orders," chapter 4 in Graham 1996). 
Chester Barnard (1938) followed in the same spirit but went well beyond Follet in that he attempted to start building solid logical foundations for a theory of what he called "cooperative systems." It is interesting that, with only a year of difference, Coase and Barnard wrote two of the most influential pieces of theory, starting from opposite ends: Coase from the optimality of the market allocations and seeing the firm as a market failure, markets being almost the efficient way of coordinating the economic activity (unconsciously, through the "invisible hand"); and Barnard from the point of view of consciously coordinating human activity through organizations.

In an often-quoted paragraph, Barnard stated that he did not began to understand organizations until he relegated the economic interests and economic theory to a secondary, though indispensable place; and these two words recognize at the same time the importance of the economic and the noneconomic factors in the working of organizations. Barnard's criterion of efficiency states that organizations should satisfy the motives of the individuals (including not only employees but also customers and possibly many of the people and groups that since then have been called stakeholders). Of course, among those motives are the economic motives (making a living, or having a reasonable return on investment, and so on) but also the noneconomic motives (e.g., in Barnard's terminology, "ideal benefactions," the "condition of communion," and so on). It is for this reason that starting from Barnard's framework has a clear advantage over starting from Coase's: with the first you never lose sight of the ends that the human beings involved pursue; while with the second you may forget some of the crucial nonquantitative aspects.

Going back to the mainstream, standard economics, the "theory of the firm" sketched in that approach is rather simple, because markets are assumed to be perfectly competitive and the firm's only function is computing the optimal combination of inputs and outputs. That maximizes profit, which is what classical welfare economics had found to be optimal for the economy as a whole. That is all there is. In fact, what are today called "stakeholders," in a perfectly competitive market, cannot be harmed in any way because, if they were harmed by a firm (for instance by being paid less than the market price), they could immediately go to another firm and sell their goods or services for the market price, one of the basic assumptions of the model being that the goods and services are indistinguishable commodities and therefore perfectly movable from one place to another. Therefore, in such markets, stakeholders cannot even be conceived.

Following in Barnard's footsteps, the so-called Carnegie School (Simon, Cyert, March and others that followed) attempted to build a new (behavioral) theory of the firm that would overcome the limitations of the classical model; and they did this starting by criticizing that model for being too simplistic in human behavior terms. In fact, in a classical book published in 1963, Cyert and March took advantage of the previous work done in 1952 by Andreas Papandreou, ${ }^{1}$ someone who at that time could be considered a conventional economist, unrelated by training to the development of management theory. Papandreou's article already looks at the firm well beyond the production function, including a Barnardian perspective on the human and motivational aspects ignored by the conventional, standard microeconomic theory. Cyert and March (1963) is today a classic, where these authors try to establish some of the principles, partly inspired in the previous work of Simon and March (Simon 1947; March and Simon 1958), on which a more comprehensive theory of the firm should be based.

\footnotetext{
${ }^{1}$ Interestingly, Papandreou many years later became the prime minister of Greece twice (1981-1989 and 1993-1996) as the leader of PASOK, the big left-wing party in Greek politics at the time that he founded.
} 
Unfortunately, even today in 2016, we still don't have a comprehensive theory of the firm that includes a realistic picture of how firms actually behave and a good account of the normative aspect - i.e., of how firms should behave for the purpose of having a better society. The reasons may still be those already enunciated by Cyert and March: disagreements about what a proper theory is, the extent to which it is defective, and the means to overcome its defects $(1963$, p. 5).

To this we may add today the later developments about firms that have become more descriptive and allegedly more "scientific" because of the massive use of empirical data. This has prevented a more comprehensive view from appearing in the intellectual picture. According to Hayek (1974), in his Nobel Prize lecture:

“[This] approach has come to be described as the 'scientistic' attitude - an attitude which, as I defined it some 30 years ago, 'is decidedly unscientific in the true sense of the word, since it involves a mechanical and uncritical application of habits of thought to fields different from those in which they have been formed.' [...] Unlike the position that exists in the physical sciences, in economics and other disciplines that deal with essentially complex phenomena, the aspects of the events to be accounted for about which we can get quantitative data are necessarily limited and may not include the important ones."

Therefore, economics has taken an "imperialistic" role in management theory (Ferraro, Pfeffer and Sutton 2005; Ghoshal 2005) and has come to dominate the intellectual picture with respect to management theory and management teaching. It is not alone: sociology is playing its role also, but economics has the upper hand. Actually, assumptions made as a matter of course in different domains of economics that might be completely harmless if interpreted as what they actually are - i.e., a first approximation (like the frictionless assumption in classical mechanics) - become in fact extremely dangerous if interpreted as a good description of reality. The reason is that, then, all the prescriptions that arise from that theory based only on first approximation assumptions become a guide to action that may lead to bad results because the other (often qualitative) variables that go beyond the strict financial ones actually operate and have a strong influence on the results of human actions. Sociology is in no better shape.

\section{Accounting and Finance in This Context}

Accounting and finance don't even exist in the context of such a simplistic theory of the firm. Or, rather, there isn't any need for them. But it is not too difficult to accommodate them by making more realistic assumptions in not-so-crucial aspects for the theory of the firm.

Let us start with accounting. The elementary theory of the firm assumes perfect knowledge by decision makers about costs and revenues, which, in reality, they don't have. Such information has to be produced and is costly. Accounting has the primary role of supplying some of this information - in a very imperfect way, we hasten to add, because the rather complex cost functions of economic theory (convex at low levels of production, concave at higher levels, and so on) can be approximated in practice only by linear functions. The familiar distinction between fixed and variable costs, where the latter are assumed to be strictly proportional to the number of units produced, is such an approximation.

This is one of the major objectives of managerial accounting. But another one is to evaluate how well the firm or any firm's subunit is doing, to see whether it is obtaining the desired results. 
The way we just presented the function of accounting gives preeminence to its managerial aspects. Generally (nowadays especially) it is financial accounting and its standard procedures that are emphasized, to the point where, in the usual textbook definitions of accounting, only financial accounting is included, emphasizing revenues and expenses (and, therefore, income, which is the difference between the two) on the one side and the financial position (assets, liabilities and owners' equity) on the other. The price a potential investor is willing to pay depends on that information, although the decision is a personal one by the actual investor and depends as well on the financial resources owned by the investor and on the attitude towards risk that the investor may have.

The income figure has classically been at the center of financial accounting and of the controversies involving it. The determination of income was intended to produce a summary figure that would be the input for the investor's decision process. In fact, before (say) the 1960s, it was sometimes assumed (naively perhaps) that it was possible to have this summary figure (which, as we will see below, cannot even be accurately determined), which would be like a "sufficient statistic," including everything that was of importance in the accounting data to make the financial investment decision. Income theory was at that time the center of financial accounting, in such classical books as those of Edwards and Bell (1961) and Chambers (1966), among others. To be sure, their theory was not naive at all and there is much today that should be learned from their analyses; what was perhaps a little bit naive was the idea that the income figure alone would be sufficient from a decisionmaking point of view. In spite of its importance, the economic reality is complex enough to require a wider analysis. The development in the 1960s of the theory of finance helped demonstrate that no valuation of firms could be done without considering risk.

Accounting had, from the beginning, another important function, sometimes underemphasized but indispensable regardless: the stewardship function. "Keeping the books" - i.e., recording what has happened in economic terms - is a helpful tool to prevent improper use (theft) of the financial resources. To some extent, one might argue that that's how accounting started in the 15th century: by keeping track of the resources spent in purchasing merchandise, taking them to a different place in caravans and selling them to other people.

Accounting thus has to be seen as a tool to (1) provide the appropriate data for decision making and (2) prevent theft. Unfortunately, we know this is not always the case, and accounting can be (and has been) used improperly - even in the opposite direction, hiding the truth and aiding theft! One of our main objectives here is to show how the misuse of accounting goes directly against the functions that it is supposed to fulfill. But for this purpose we need to turn now to the function of finance.

As stated above, in standard classical economics finance does not even exist. There is land, there is capital, there is labor, there might even be entrepreneurship, but financial resources are not necessary for the conventional theory of the firm briefly sketched above. Obviously, finance does in fact exist, and it is important, but it is not too surprising, in the context of the classical model, that the theory did not start until well into the 20th century. It came about through the study of investments - i.e., those decisions that have to do with more than one time period. Irving Fisher (1930) may be considered the founding father of the discipline. Uncertainty is another key word in this development; and the theory of finance was set forth as such for the first time by Fama and Miller (1972). Finance, from this point of view, should be considered as an auxiliary discipline of the theory of the firm, to make possible the activities of this entity by finding the appropriate resources at a reasonable cost proportionate to the risk of the firm. 
The theory of investment amounts in practice to making investment decisions based on the techniques of discounted cash flows (DCF) and, as a corollary, the value of the firm at some point in time should be the present value of the cash flows obtainable from the firm from that point in time to infinity. This theory (correct, from a formal point of view) led to amplifying the objective of profit maximization to that of value maximization. Often, in articles and in annual reports, it is expressed as "maximizing shareholder value" (which is an objective that is technically incorrect because shareholder value by itself does not take into account risk, which is a crucial variable; in fact, in the Great Recession, many unfortunate decisions were made by forgetting about risk considerations, for instance, in subprime mortgages).

It seems that the expression "shareholder value" was used for the first time by Alfred Rappaport (1986). Interestingly, Rappaport's idea in that book was not to give preeminence to shareholder value over everything else, but he, as a good accounting professor, was worried about the income figure calculated by the standard accounting procedures being a poor indicator of the performance of the firm, mainly because of the effects of a decision in the long run. There are many examples of that, but the area of capital budgeting is perhaps where it is clearer: between two investment projects, management should choose the one that gives a higher present value of the project's cash flows, but it is not uncommon to find that this is not done because the project with higher present value is also the one that produces less accounting profits in the short run; and if managers are being evaluated (perhaps among other variables) by profit, they would be penalized if they made the right decision for the firm. So, they often would make the "wrong" decision, perhaps by tampering with the numbers to convince top management - an improper and therefore unethical use of accounting, of course. So, Rappaport's idea was that the criterion for making investment decisions had to be the impact of the investment on shareholder value (and, therefore, calculated through discounted cash flow methods) instead of looking only at short-run profits, not instead of looking at other stakeholders' interest. This was even made more explicit in Rappaport (2006). Unfortunately, there are many uncertainties in making this type of decision and, so, shareholder value in the short run is seldom a good guide; and this is one of the reasons (perhaps the most powerful one) that led to a misuse of the concept. Jack Welch, who was for a while a staunch defender of shareholder value and had helped popularize that notion from the beginning, came to see later that this was "a result, not a strategy" and that using it in the short run for decision making was “a dumb idea” (Welch 2009).

Financial accounting and finance are, then, closely related to each other. Financial accounting may be defined as the information that is needed to make financial decisions and, thus, both of them should respond to the common objective of raising financial resources from the market at a reasonable cost and obtaining from them adequate profitability; managerial accounting should contribute to achieving that second goal.

\section{The Inversion of Values}

But let's go back to the standard, neoclassical economic theory. Suppose now that we accept as true all the assumptions of that approach. Namely, that (1) there are perfectly competitive markets for all products and services (especially labor), (2) there are perfectly known production functions, and (3) if there is uncertainty, the utility functions of consumers are such that they obey the rationality principles expressed in the axioms of von Neumann and Morgenstern (1944) or other similar formulations. Then, the welfare economics theorems tell us that firms should actually maximize profits in order to obtain an outcome that is Pareto optimal. Whether this happens in 
a one-period model or in a multiperiod model is just a technicality: time discounting allows for having an allocation that is efficient (in the Pareto sense) by maximizing profits in any case. Besides, markets being complete (i.e., there are markets for all commodities, including contingent commodities under uncertainty), profit is perfectly well defined and measurable without ambiguities. In fact, under these assumptions (perfectly competitive and complete markets, unbounded rationality, perfect knowledge of the production function), there is no distinction between the long-run profit of the firm and its value.

The conclusion is therefore easy: assuming these assumptions hold true, if we want to have a Pareto optimal allocation for the economy as a whole, firms should maximize profits (or value, which is mathematically equivalent). This, together with rational behavior on the part of the consumers, will ensure that an efficient outcome in the Pareto sense is achieved.

Of course, a Pareto optimal outcome may not be one we like if we value some other factors such as "equality," "fairness," or "justice" in the distribution of income; but it is often argued that, in order to fix that problem, all we have to do is to engage in some type of redistribution via taxation. Therefore, firms maximizing profits are something that can be considered "good." With unbounded rationality and perfectly competitive and complete markets, the only "residual" variable is profit, so maximizing profit can only be good. Indeed, if the markets for all inputs and outputs (including, of course, labor) were perfectly competitive, there would be little else that a firm could do. Its knowledge of the technology and the ability to apply it would condition its efficiency; but, then, efficiency would be only a matter of knowledge on the part of the firm: the more efficient it is, the higher the profits it can achieve, and the "marginal" firm that has higher costs is bound to disappear. Besides, as I mentioned above, by doing that, the firm cannot harm anybody else; all other agents (or stakeholders) are perfectly protected by the markets. Employees cannot be paid less than they deserve because, with a perfectly homogeneous type of labor, they could go to another firm for the prevailing market salary; and the same thing would be true for suppliers, financiers, and all other stakeholders. Even the government and the public interest would be protected by perfectly competitive markets: by the Coase theorem (Coase 1960), if all parties involved can reach and enforce agreements with no transaction costs, the final outcome will be efficient.

All these hypotheses together, then, and profit maximization are a sufficient condition for economic efficiency in the Pareto sense. Then, it follows that if these hypotheses hold, firms should maximize profits in a one-period situation, or value in a multiperiod setting, in order to obtain a social optimum. But the converse does not hold - i.e., if all these hypotheses are not true, then profit maximization may not be a good objective for the firm from a social point of view. In fact, affirming that it actually is a means of obtaining social efficiency is an instance of the logical fallacy called "affirming the consequent." Let's use $P$ to identify the set of hypotheses above: perfectly competitive and complete markets, perfectly known production functions, and perfect rationality in the utility functions of individuals; $Q$ will then be profit maximization and $R$ social efficiency. Suppose now that we accept the formal implication that, if $P$ and $Q$ are true, then $R$ must be true. This does not mean that $R$ implies $P$ and $Q$ : this would be affirming the consequent. In fact, in realistic terms, $P$ is, in general, false; and so $Q$ alone cannot guarantee $R$. Rather, the correct logical inference is that if $R$ is false - i.e., if the outcome is not efficient - then it must be that either $P$ is false or else $Q$ is false; and knowing that $P$ is in general false does not allow us to say anything about $Q$.

In more intuitive terms, the set of conditions $P$ and profit maximization $Q$ are together sufficient conditions for social efficiency, but they are not necessary - i.e., one can have $R$ without $P$ and/or $Q$. Furthermore, profit maximization alone cannot guarantee social efficiency; if the conditions 
in the set $P$ are not met, then profit maximization may even harm other individuals or institutions, as we intend to show below.

Before we get into that problem in more depth, I want to stress the fact that the measurement of profit (or value, for that matter) has important problems in practice. The accounting literature has shown that, when markets are incomplete or imperfect, income measurement may well be meaningless (Beaver and Demski 1979), because the concept of value itself may not be well defined; therefore, profit maximization may be meaningless in the short run even with more reason. This is not, then, a matter of opinion or values or ideology: it is a purely technical matter. In a realistic setting of imperfect, incomplete markets and bounded rationality, you may not be able to calculate short-term income with a reasonable degree of precision (let alone long-term), and therefore profit (or value) maximization may simply be impossible to achieve. And, of course, it cannot be then a guide for decision making and, therefore, cannot be a valid and operational goal for the firm, as the above quote from Jack Welch suggested. Anthony (1960) already saw these problems more than 50 years ago, when some of these formal concepts had not been developed yet, but in a more intuitive, practical way he argued that profit maximization was "too difficult, unrealistic and immoral."

Therefore, taking profit (or value) maximization as the objective of the firm is an inversion of values. What is really desired is an outcome that is socially efficient, for which profit maximization and other assumptions are sufficient conditions. Instead, when we propose profit maximization we accept that profit (or value) maximization is something desirable by itself.

One of the reasons why it may not be desirable in general is precisely the problem of (possibly) harming other parties. Just to see the most obvious example, let us briefly examine the relationship between the firm and its employees. Perfectly competitive markets do not exist for any product, input or commodity, but in the labor market this is particularly true, mainly in a sophisticated environment such as the one we enjoy nowadays. If a firm has a differentiated strategy and a distinctive competence (which is what may permit the firm to make a healthy profit and survive indefinitely), the type of labor it needs is not a "commodity" at all but people possessing distinct knowledge and abilities that are not found in the market. Or, in other words, employees, to be really useful to this kind of firm, have to invest in a type of knowledge and abilities that are very useful to them if they work for that particular firm but may not be useful at all if they work for another one. And once they have invested in this knowledge, the firm may exploit them by behaving "monopolistically"; it is the only firm that demands this special knowledge and abilities. Thus, the firm may change the work conditions in a way that is unfavorable to those employees. Some economists would argue that this is not in the best interest of the firm in the long run and that this will affect the long-run value of the firm unfavorably. But profit, as we mentioned, is not very well defined even in the short run, and therefore it cannot be measured with any precision in the long run, and the same is true for the value of the firm. Individuals with bounded rationality, different from the all-knowing and all-anticipating homo economicus, may not be able to recognize this because they don't have a measurable variable that can serve as a guide; and, also, they may fall victim to the "bird in the bush" type of fallacy: tomorrow I might have two birds, and today I have only one, but homo economicus takes the bird today and doesn't call this behavior irrational but rather "having a high discount rate."

This may happen with any of the other stakeholders as well. Decisions made by a firm that attempts to maximize profit or value, then, may be beneficial to some of them (perhaps shareholders, if they are the declared priority) but harmful to others (employees, suppliers, financiers, or any other stakeholder group). Consequently, there is no guarantee that the result will be Pareto superior to 
the previous situation; but even if it is, it is not value-free at all. This happened because we systematically wanted to benefit one group of stakeholders (the shareholders) over the others: the assumed "scientific," "value-free" basis of profit or value maximization simply vanishes when you look at it this way. Then, the inversion of values is only one step ahead: profit or value maximization becomes the goal instead of Pareto efficiency and/or fairness or justice.

A recent article in the Journal of Financial Economics (He and Tian 2013) purports to show this inversion of values empirically: firms that are covered by a greater number of financial analysts produce a smaller number of patents. The authors' interpretation of those results is that more coverage by analysts means more pressure from the financial community to increase current profits. This results in increased efforts by management to meet short-term goals. And these efforts are a barrier to them investing in long-term innovative projects and thus endanger the future of the company.

In summary, long-run profit or value maximization is seldom a good operational objective for the firm, because these variables are not measurable with precision, among other reasons. While we would all want Pareto efficiency (Pareto inefficiency is of course much worse!), most people would also want some notion of fairness or justice (see Cugueró-Escofet and Rosanas 2013 and 2014 for an analysis of these concepts in a management control situation) and the objective of profit or value maximization in the short run guarantees neither. Thus, insisting on profit or value maximization at the possible expense of Pareto efficiency and/or justice is an inversion of values that is simply preposterous. In its Latin etymology, the word "preposterous" means putting the last first and the first last, which is exactly what we have just shown that attempting to maximize profit or value does. We have to put the objective of Pareto efficiency and fairness first; and, if we do it properly, then, profit or value maximization in the long run may have to be achieved as a consequence.

\section{The Concept of External and Internal Missions}

It is probably true that many entrepreneurs start their own firms because of the profit motive. But notice that the statistics about survival of new firms are rather dismal. The available statistics one would like to have are difficult to obtain but, in the United States, according to the webpage of the U.S. Small Business Administration, no more than 50\% of new firms last more than five years; and only about 30\% survive 10 years. European survival rates in general, and Spanish rates in particular, albeit mainly in times of crisis and less reliable, are clearly worse: according to some accounts, 50\% of new firms would fail in their first or second year, and 95\% would not go beyond their fifth year. Interestingly, the probability of survival seems to increase with age, which in view of what we are going to argue next should be only logical.

There are, of course, many reasons for the failure of start-ups, among them a lack of experience, deficient financial planning, and insufficient resources, but one factor seems to be crucial for success: having a passion for what you do and having determination and patience. Beginning with the idea of making a lot of money is not a good way to start. It is much better to start with an idea of a way to satisfy consumers' needs that they'll be willing to pay for. In other words, one must have a clear idea of mission.

Most firms today consider it appropriate to include in their annual reports a mission statement that supposedly should be a brief statement expressing the raison d'être of the firm. Unfortunately, many of the mission statements published in annual reports are just a set of empty, beautiful words that at best mean nothing and at worst simply emphasize "maximizing shareholder value" as the 
main objective of the firm, in the sense of this being its first and only priority (Rosanas 2013, chapters 6, 7 and 10). Yet the concept of mission is a powerful one, one that in the context of what we are discussing here (the functions of accounting and finance) may be crucial.

A mission for a firm cannot be something like maximizing shareholder value: it has to be something that expresses what the firm wants to do for its customers and how it plans to do it, so that it can then be a guide for all the decisions that the members of the cooperative system called "the firm" have to make. But from this point of view, and if we consider with Chester Barnard (1962, chapter 1) that, besides employees, customers are members of the organization too, we will have to attempt to satisfy the needs of these two types of members. This then leads us to distinguish between two kinds of missions: internal mission and external mission, depending on whether we are considering employees or customers (Rosanas 2013, chapter 7). To do that, we may go back to the Barnard approach and look at organizations as systems of cooperation that should satisfy the motives of the individuals - i.e., in his vocabulary, they should be "efficient." Then, and if we think first of the employees of the organization, the idea of internal mission originates very naturally: to be "efficient" and endure, the firm must satisfy the motives of the employees. Let us stress that we are talking about their real motives, not only their impulses or their caprices: the firm has to do something for them that makes them happy afterwards, as a consequence of their actions. Barnard's concept of efficiency is important here. It consists of saying that an action is "efficient" if it doesn't have unsought unfavorable consequences that more than offset the positive consequences that were pursued by the action, -i.e., that satisfies their motives. For an individual, this essentially may mean a great workplace, where everybody can make a living, where all employees can trust each other, where they feel proud of what they do and enjoy doing it. In practice, it may often mean doing something that requires an effort, and thus may not look attractive at the outset, though its effects will be satisfactory afterwards. If you always do something that requires no effort, it is not demanding and you don't learn anything doing it; in fact, you easily get bored. What most people want is to be in a situation where you get in the habit of making efforts to achieve something that is worth achieving and you are a member of a community where all members trust each other and the management at the same time.

The second group of members of the organization is its customers. Then, along similar lines, what comes up quite naturally is the idea of external mission: the firm has to attempt to satisfy the real needs of the customers - again, not their caprices or their impulses but what is actually useful to them. The external mission is typically the trigger of the firm at the time of its foundation: the entrepreneur sees some need that is not fulfilled by other firms, which becomes an opportunity for him/her. The profit motive, of course, often helps; but if the idea the entrepreneur has is not something that really satisfies customer needs, soon the firm is going to fail. No matter how strong the demand for the firm's products seems to be at the beginning, if what it produces and sells is simply a "fad" it may be among the firms that disappear before reaching the second or third year. This was one of Barnard's fundamental ideas: a firm, to survive, has to be effective (achieve the explicit goals it has set for itself) and efficient (in his meaning of satisfying customers' and employees' needs).

To put an idea into practice, one needs to build a human team that is capable of doing it and willing to do it as well. And in order to do that, you need a strong sense of internal mission: if your employees do not identify with the organization, you won't succeed in having them satisfy the customers' needs. No "metric" or system of incentives in the world is able to do that (CugueróEscofet and Rosanas 2014). Rather, formal systems of performance measurement and incentives tied to these measurements through a formula typically deviate employees from their main 
obligation, which has to be the external mission (satisfying some type of customers' needs) because those needs have crucial qualitative aspects.

It is important to stress at that point that the external and internal missions are interrelated: you cannot have one without the other. Historically, there have been firms that have started with a strong sense of external mission and reached the conclusion that they needed the internal mission, and others where the converse has happened - i.e., they have started with a strong sense of internal mission and developed an external mission that they needed to make the endeavor feasible.

Southwest Airlines may be a good example of the first type: Herbert Kelleher (and Colleen Barrett as his secretary, who later became the CEO of the firm) started the company to help customers have a pleasant trip on a friendly airline, always arriving on time or earlier than scheduled and not spending money giving customers drinks or food they didn't need. For that purpose, they had to treat their employees (who are considered the company's first customers) very well. Barrett (2008) would say that 85\% of her time as CEO was spent delivering customer service to her employees, so that she could expect the employees to treat external customers similarly. If they do that, the customers will keep coming back to the firm. Then, with a reasonable business model, the shareholders will be happy, because they will make a profit. This is a model of putting first things first and last things last. First, there are employees; second, customers; and third, shareholders. To keep them all happy you need to have this order of preference. If you start with the last, it is very likely that the pressure for quick returns will result in cost cutting and employee dissatisfaction, which in turn will result in customer dissatisfaction. This is the vicious cycle that has to be broken by putting employees first.

La Fageda may be a good example of a firm that started with a strong sense of internal mission. Cristóbal Colón, its founder, started the firm as a cooperative intended to provide jobs and a meaningful life to people who are mentally disabled. He was a psychologist who said he had never seen a mentally disabled individual "get cured" in the usual healthcare institutions. So, he decided that starting a cooperative would be the way to provide such people with meaningful work. But, of course, he needed an external mission. He soon found one: to be an integrated producer of high-quality dairy products (mainly yogurt) for the Catalan market. The cooperative's products are better than those of the big brands and this increases the employees' pride in their work. The cooperative has been extremely successful for quite a while, and there is no sign that it will not continue to be so.

So, the internal and external missions come first, and returns to the shareholders come last. That is the right order. Putting shareholders first is simply preposterous.

\section{What Can Go Wrong? Almost Everything!}

In order to put first things first and last things last, then, finance must be an instrument for a firm (or, in general, the real economy) and financial accounting must be an instrument for finance. This is the "right" order of priorities. I don't include managerial accounting in the analysis because the main problems related to ethics that there may be in managerial accounting have already been analyzed in other papers (Cugueró-Escofet and Rosanas 2013 and 2014). The firm's role in society in the context of microeconomics must be that of a Pareto improvement i.e., going from a given situation to another one where nobody loses and someone gains (internal mission and external mission); therefore, no financial or accounting decision should endanger this possibility. But often they do. Typically, everything starts with a decision that looks "right" 
from some point of view (financial, for example) but that endangers the internal and external mission of the firm. Then, if the environment of the firm becomes more demanding, unethical behavior is only one step away. Some examples from the real world may be the best illustration of all that, but to be rigorous it is good to list first the types of decisions that can be made in the financial and accounting fields, and then comment on each of them.

1. Decisions on capital structure and issuing equity or debt

2. Decisions about real investments by firms - i.e., capital budgeting decisions

3. Dividend policy

4. Short-term financial decisions

5. Accounting policy decisions

6. Real economy decisions that affect the accounting reports

The first, third and fourth types of decisions are the corporate finance decisions that, according to some famous theorems in theoretical finance (Modigliani and Miller 1958), are irrelevant. They may be irrelevant in an economy of all-knowing, unboundedly rational decision makers, but they surely aren't irrelevant for real-world, boundedly rational decision makers. Let's see what can go wrong with them.

Panrico (real name) is a Spanish firm that was founded in Barcelona more than 50 years ago by a baker (Andreu Costafreda) who saw a business opportunity in producing and distributing fresh doughnuts every morning when he went to the United States in the early 1960s. Doughnuts (or donuts) were not known or available in Spain at that time, and Panrico registered the name "Donuts" as a trademark. It was highly successful and it quickly expanded in terms of products to other pastries and geographically to other regions of the country and to foreign countries in the following years. Its products were considered high-quality products and were very well valued by customers. In 2005, a private equity firm (Apax) bought Panrico through a leveraged buyout for $€ 900$ million, a price most people felt was too high, since the firm had a turnover of about $€ 600$ million and was making a profit of about $€ 20$ million. So, immediately after the purchase, and since the debt was now about $€ 600$ million, it was difficult to see how financial costs could be covered, even in times of low interest rates. And, of course, the firm had difficulties from the beginning. Very poor decisions were then made (selling all the foreign subsidiaries, changing the essential product - the Donut - from fresh to wrapped in plastic to cut on distribution costs, etc.), and the crisis didn't help. So, the firm was then bought by another (vulture) fund and is now in the process of restructuring, the end of which is difficult to predict. But it has had huge losses and an eight-month strike, so things do not look good. If the firm has to close down (not an unlikely prospect), about 4,000 jobs will have been lost in total, and lots of money in between.

Is this a case of ethics, a case of professional incompetence, or both? Why did the private equity firm buy at such a high price? Because it thought it could improve profitability and sell Panrico for a higher price. But this did not happen, essentially because the debt made the firm unprofitable in the very short run, and the cost-cutting actions made things worse, clearly deviating the firm from its external (and next the internal) mission: the product did not satisfy customer needs in terms of quality, freshness, etc. So, when it became merely an instrument to make money for the shareholder, it failed to do so, harming a lot of people in the middle, from employees to suppliers and customers and, of course, the private equity firm that bought it and the financial institutions that lent the money. There is, of course, some degree of incompetence: thinking that one can change the product and cut costs arbitrarily and that the customers will continue to buy is at best naive. Also, there is a little bit of bad luck: the crisis didn't make things better. But it is clearly a 
case of an inversion of values: the firm, at the beginning, had a clear sense of mission and of social usefulness towards the customers, offering them a good product they were happy with, and this was its priority; and, next, the only priority was the financial situation, and cost-cutting decisions were the instrument, negatively affecting almost all the stakeholders. Those decisions would have not been necessary if Panrico had not had such a high level of debt. Even without the crisis, this is incompetent and unethical. The first ethical obligation that anyone has in the world of management is to be professionally competent.

With respect to the second point (real investments in firms), I'm going to be rather brief. In fact, I have already mentioned that sometimes investment projects that are good in terms of discounted cash flows (which is the right criterion for investment decisions) are not undertaken because the accounting profits in the first two or three years are low or even negative; or some bad projects are accepted because they promise good profits in the first years, but they become worse as time goes by. Why would managers do this? Two reasons: first, their compensation may be partly based on the accounting profit (directly or indirectly, perhaps through the stock exchange price of the company's shares, which is based on analysts' assessments based on profits - often as short-run as quarterly earnings); second, profits make managers look good, and their future may depend on how they look today. Now, this is not often thought to be an ethical problem, but it is: these are decisions made to benefit a few at the expense of all the other stakeholders, including society as a whole, which has to put scarce resources to use where they are not profitable.

With respect to the third point, dividend policy, again it is difficult to draw the line between what is simply a bad technical decision and unethical behavior. It is not unusual to find a holding company in financial stress draining the resources of one (or more) of the profitable companies it owns, shifting part of the stress to these profitable companies and putting them at risk. Again, in Spain, we have what seems to be a good example of that: Cacaolat was created as a family business but expanded quickly because it had an excellent product (a drink essentially made of milk, cocoa and sugar) that was quite successful in Catalonia. In 1974 it was sold to another firm in the business of milk products, and finally in 2007 it was sold to Nueva Rumasa, a holding company that had serious financial problems. It was then that it was decapitalized and put into financial strain for the benefit of the parent company, to the extent that it ran the risk of disappearing until an alliance of two other firms (Damm, a beer company, and Cobega, the bottler of Coca-Cola) bought it and made it profitable again after considerable investment. Again, one may doubt whether what happened there is just incompetence or unethical behavior. But once again what is clear is that Cacaolat, under Nueva Rumasa, lost its sense of mission and faced risks it should have never faced, putting at risk many jobs and hurting other stakeholders as in the previous example.

Our fourth point, short-term financial decisions, does not present as many dangers as that of longterm decisions, but it is the interface with accounting problems. In the main, the type of problems we can find there (besides, of course, incompetence, which is always the first ethical problem) are those to do with the truthfulness of the information given to the financial institutions and how the financial institutions interpret that information. There, you can create a vicious cycle (I lie to the bank because I believe that the bank is not going to believe my statements, and so I tell them I'm in better shape than I actually am and the bank disregards the information for that reason, and so on and so forth) or a virtuous cycle (I tell the truth, the bank believes me and the bank believes me because I tell the truth, and I tell the truth because I know the bank believes me). Quite obviously the second is better yet very difficult to achieve, sometimes because of competitive pressures and the incentive systems facing the managers of the two firms again. 
Our fifth point has to do with accounting. Accounting is a language, an imperfect one as we have already implied above. The truth can never be described entirely, and in fact there may be different (authentic!) views of the same truth. Now, some of them may be perfectly legitimate, but others may not. What is usually called "window dressing" (taking some actions towards the end of the year that will make the balance sheet look better, even though the reality is unchanged) is again at the limit. A manager may be convinced that the firm has good prospects and that the balance sheet does not reflect this - and so, it is unlikely that a bank will lend the firm the money it needs. Then, window dressing may be something one is almost forced to do, under the circumstances. But window dressing may, in other occasions, simply be a big lie. It is impossible to draw a clear line to separate one type of situation from the other. In fact, the bank may be to blame because if it paid attention to factors other than the numbers, which can reflect reality only partially, and if it were willing to see whether the projects the firm has make sense from the point of view of its mission, this would probably not happen. But unfortunately, there are powerful incentives not to do that. Any investment by a bank in a firm is a risk for the bank; and if things go sour and the bank loses its investment, everybody will blame the official who has given the loan... unless the balance sheet was "right." So, the firm may have to lie to obtain the loan. This is a complex system of social incentives that unfortunately often push people in the wrong direction.

Of course, at the extreme end, there is fraud: preparing financial statements that are in fact downright false. This is often done when the situation is desperate. In the Bausch \& Lomb case, a warehouse in a secret place was used to store products that according to the financial statements were sold, when in fact they were not. Quite clearly, this happened in that firm because of the pressure to obtain higher accounting profits every year.

But again, drawing a line between what is ethically acceptable and what is not is a very difficult thing. In another one of the big scandals of recent years - Enron - some unorthodox accounting practices were used, for instance, at the moment of signing a contract to supply gas to a city for a number of years, recognizing at this very minute the profit of the whole contract by using a DCF valuation of the contract. Enron was able to get this practice accepted by the auditors because the company argued that nowhere was it forbidden, that both accounting theory and accounting practice in the previous years had gone in the direction of valuing assets at the market price, and that the DCF technique was the way to calculate a synthetic market price for a contract that didn't have one. Of course, a few years later it became evident that Enron's assets were clearly overvalued because of the practice just described and many others. It is difficult to draw a line, but at some point in time it became evident that Enron had crossed it.

Finally, the sixth point has to do with taking real action to change the numbers. This is what has been called in the accounting literature the "economic consequences" of accounting standards and regulations (see, e.g., Rappaport 1977; Zeff 1980). It is an extension of what we discussed in our second point: the fact that accounting practices, no matter how sound, may lead managers to make poor decisions because those practices may make a good alternative look worse than a bad one.

\section{Are There Any Solutions to All of These Problems?}

The way we have described the problems presented above already gives some indication that a clear solution is going to be difficult to find. Many of the unethical actions described are not thought-out and well prepared from the beginning. They just happen, often after the firm is in a difficult situation because of incompetent decisions that have been made. Then, under the 
difficulties, many managers make decisions that they would not make under normal circumstances because of the pressure for financial results in the short run. We have illustrated this type of situation with the cases of Panrico and Cacaolat.

The nonsolution that comes to everybody's mind when dealing with this type of scandal is to enact legislation to prevent events like these from happening - or, within the firm, to establish a (new or improved) set of rules to do with permitted or forbidden practices. Certainly, this may occasionally be part of the solution but it is seldom the whole solution, and it may even be harmful. Sitkin and Bies (1993) have shown how the legalistic organization often creates four paradoxes (power, rationality, formalization and justice) by which the dysfunctional effects of legalization may actually reduce justice and thus possibly create a spiral of legalization that leads to less and less justice: "law without justice," to use their own expression (Bies and Sitkin 1993).

While this is always true, it should be even more obvious in the problems described in the previous section. When we deal with managerial decisions that do not have a technical solution, such as decisions on capital structure, investment decisions, dividend policy, short-term financial decisions and accounting policy decisions, no strict rule is possible that will always lead to good results. Professional competence is the detailed knowledge needed that permits decisions to be made that depend on very specific circumstances and that are at the root of the working of a market economy (Hayek 1945).

Thus, one essential condition (necessary, but not sufficient) for these problems not to happen is, in any context, professional competence: if you are incompetent, it is unethical to be in a position to make decisions in a company that affect other people, as happens with practically all management decisions. Perhaps in the financial area this is truer than in any other field: finance has been qualified as being "the physics of management" in the sense that it is the area where theory is more developed and formalized, but knowing the theory alone is not sufficient for making good decisions. It has to be applied with prudence, taking into account the limitations of the financial models and the aspects where the nonquantitative variables may be crucial and making decisions based on the "whole picture" is crucial. This naturally extends to the accounting area, even though accounting does not have as developed a theory as finance does: accounting numbers (if prepared in good faith and according to the generally accepted financial standards) express important parts of the reality of a firm, but they are very incomplete. They may be extremely helpful in diagnosing a business situation but, if used and followed blindly, may lead to disaster. And the interface between finance and accounting is particularly dangerous if this is not taken into account: publishing short-term numbers such as quarterly earnings, using them automatically to value securities in the stock exchange, and making financial decisions based on that without other considerations is extremely dangerous. In the Enron case, just a few months before the firm went bankrupt in July 2001, analysts were still recommending buying shares in Enron at a price (about $\$ 60$, or more) higher than the market price was at that time (about $\$ 40$ ), based on the past trends of earnings and on the quarterly reports. In fact, in November the price fell to less than $\$ 1$ and the firm filed for bankruptcy in December. The pressure to obtain higher and higher results led Enron to fraudulent reporting, grossly overvaluing assets, hiding liabilities through subsidiaries and consequently overstating earnings and owner's equity.

The second condition (sufficient, but not necessary) is that management must have a clear sense of both the external and internal missions, and make decisions accordingly. As stated above, both the external and internal missions have to be defined in terms of the kinds of customer needs that the firm intends to satisfy, and the second in terms of identification with the firm's objectives. This, of course, has many aspects that are not quantitative and therefore cannot be measured 
with any precision. And what is more important is that financial and accounting decisions have to be subordinate to them. When a firm uses accounting practices that tend to overstate income so that the stock exchange reacts positively, it starts down a path that will very likely lead it towards more and more difficult quantitative indicators and finally to accounting fraud.

An important point in this context is that of course the firm has to survive in the short run; and so the financial and accounting decisions that have to be made must be able to accomplish that. Effectiveness, in Barnard's terms, is absolutely necessary for that purpose and effectiveness has to do with many of the quantitative indicators that are often used. So, professional competence means knowing that there is a minimum value of those indicators that has to be exceeded for short-run survival. The mistakes that often lead to a dead end are attempting to maximize those indicators (mainly accounting profit and through that the value of the stock), disregarding the idea of external mission. Then, as we have described before, customers are not satisfied, and it becomes more and more difficult to achieve the quantitative goals, and this pressure leads to unethical behavior. Professional competence means in fact being able to find alternatives that are satisfying from the point of view of the quantitative indicators (not maximizing, which is actually impossible and detrimental to the future) and go in the direction of the external and internal missions at the same time.

Internal and external missions always have to go together, because they are based on the same kind of motives. A person who has only extrinsic motives (i.e., is motivated only by money or monetary equivalents) will never attempt to satisfy customers' needs or identify with the organization. This is homo economicus: his behavior will only follow the incentive systems and, since these are based only on quantifiable variables, the real needs of the consumer will not be taken into account - only the explicit, tangible, measurable results.

An important warning is in order here. In a society and a business community that in the last decades have become obsessed with effectiveness, we often see management systems based exclusively on measurements and incentive systems to enhance that effectiveness; and then management "preaches" ethics or even establishes an ethical code that is intended to prevent exactly the type of behavior that the formal measurement and incentive system is promoting. This of course can never work: pushing people in two different directions at the same time can only succeed in confounding the employees.

Consequently, the problem is not (as it is often presented) a matter of trade-offs between a firm's value and other objectives (those of the other stakeholders or those of society). It is rather a problem of professional competence and the right order of priorities in order to achieve long-run results both for the firm and for society.

Intrinsic motives as such (i.e., those to do with doing a good job or enjoying work itself) don't help too much: a member of the organization motivated exclusively by this type of motive would obviously pursue satisfying them and may match the consumers' or peers' needs only by a fortunate coincidence. Just think of the perfectionist engineer trying to create an impeccable, but very expensive, product when what is needed is a product customers can afford.

So, we can rely only on one type of motive: the ethical motives to do with being genuinely interested in other people's needs. Pérez López (1993) called them "transcendental" and Rosanas (2008) called them "transitive" to indicate in both cases that the objective of such motives is the other person, consumer or employee. It is the only way that the members of the organization will really pursue the objective of satisfying other people's needs. Therefore, an organization must promote this type of motive. Unfortunately, this cannot be done through specific actions as in a 
mechanistic system. Rather, management should create an internal climate in the organization where these motives can grow and, above all, do nothing that prevents them from growing. Very specifically, emphasizing extrinsic motives has been shown to be a very effective way of displacing the intrinsic and transitive motives (Frey 1993; Osterloh and Frey 2003), mainly if the rewards based on measured performance are relatively high.

In summary, there is no ready-made solution to the problems of ethics in finance and accounting. Rather, one has to establish the conditions necessary for an ethical spirit to develop. First, professional competence; next, a strong sense of mission; and finally, helping promote the transitive motives through creating a climate where they can develop and avoiding being displaced by strong extrinsic motives. 


\section{References}

Anthony, R. N. (1960), The Trouble with Profit Maximization: It Is Too Difficult, It Is Unrealistic, It Is Immoral, Harvard Business Review, 40 (6), pp. 126-134.

Barnard, C. (1938), The Functions of the Executive, Harvard University Press, Cambridge, Mass.

Barnard, C. (1962), Organization and Management, Harvard University Press, Cambridge, Mass.

Barret, C. (2008), Southwest Airlines' Colleen Barrett on “Servant Leadership." YouTube video, 25:00, from an interview given at the Wharton School of Management of the University of Pennsylvania in 2008, posted by "KnowledgeAtWharton," July 9, http://www.youtube.com/watch?v=6TgR95vnM0c accessed in May 2014.

Beaver, W., and J. Demski (1979), The Nature of Income Measurement, The Accounting Review, 54 (1), pp. 38-46.

Berle, A., and G. Means (1932), The Modern Corporation and Private Property, Macmillan, New York.

Bies, R., and S. Sitkin (1993), Law Without Justice: The Dilemmas of Formalization and Fairness in the Legalistic Organization. Employee Responsibility and Rights Journal 6 (4), pp. 271-275.

Chambers, R. (1966), Accounting, Evaluation and Economic Behavior, Prentice-Hall, Englewood Cliffs, N.J.

Christenson, C. (1976), Proposals for a Program of Empirical Research into the Properties of Triangles, Decision Sciences, (7), pp. 631-648.

Coase, R. H. (1937), The Nature of the Firm. Economica, New Series, IV, pp. 386-405.

Coase, R. H. (1960), The Problem of Social Cost, Journal of Law and Economics, 3, pp. 1-44.

Cugueró-Escofet, N., and J. Rosanas (2013), The Just Design and Use of Management Control Systems as Requirements for Goal Congruence, Management Accounting Research 24 (1), pp. 23-40.

Cugueró-Escofet, N., and J. Rosanas (2014), The Ethics Of Metrics: The Effects On Behavior Of Performance Indicators, Paper presented at the 18th International Symposium on Ethics, IESE, Barcelona.

Cyert, R., and J. March (1963), A Behavioral Theory of the Firm, Prentice Hall, Englewood Cliffs, N.J.

Dermer, J., and R. Lucas (1986), The Illusion of Management Control, Accounting, Organizations and Society, 11 (6), pp. 471-482.

Edwards, E. O., and P. W. Bell (1961), The Theory and Measurement of Business Income, University of California Press, Berkeley and Los Angeles.

Fama, E., and M. Miller (1972), The Theory of Finance, Dryden Press, Hindsdale, Ill.

Fisher, I. (1930), The Theory Of Interest As Determined By Impatience To Spend Income And Opportunity To Invest It, The Macmillan Company, New York. 
Follet, M. P. (1925), How Must Management Develop in Order to Become a Profession, Chapter 11 in Graham (1996).

Frey, B. (1993), Does monitoring increase work effort? The rivalry with trust and loyalty, Economic Inquiry, vol. XXXI, pp. 663-670, October.

Ghoshal, S. (2005), Bad Management Theories are Destroying Good Management Practices, Academy of Management Learning \& Education, 4 (1), pp. 75-91.

Graham, P., ed. (1996), Mary Parker Follet, Prophet of Management, Harvard University Press, Boston, Mass.

Hayek, F. A. (1945), The Use of Knowledge in Society. American Economic Review, 35 (4), pp. 519-530. September.

Hayek, F. A. (1974), The pretence of knowledge. Nobel Lecture, The Nobel Foundation, Reprinted in American Economic Review, 79 (6): pp. 3-7.

He, J., and T. Xuan (2013), The dark side of analyst coverage: The case of innovation, Journal of Financial Economics. 109 (3), pp. 856-878.

March, J., and H. Simon (1958), Organizations, John Wiley and Sons, New York.

Modigliani, F., and M. Miller (1958), The Cost of Capital, Corporation Finance and the Theory of Investment, American Economic Review, 48, pp. 261, 264.

Osterloh, M., and B. Frey (2003), Corporate Governance for Crooks? The Case for Corporate Virtue, Working paper ISSN 1424-0459, Institute for Empirical Research in Economics, University of Zurich.

Papandreou, A. (1952), Some Basic Problems in the Theory of the Firm, In Haley, B. F. (ed.), A Survey of Contemporary Economics, Richard D Irwin, Homewood, Ill.

Pérez López, J. A. (1993), Fundamentos de la Dirección de Empresas, Madrid, Ediciones Rialp.

Rappaport, A. (1977), Economic Impact of Accounting Standards - implications for the FASB, The Journal of Accountancy, 143 (5), pp. 89-99.

Rappaport, A. (1986), Creating Shareholder Value: A Guide for Managers and Investors, The Free Press, New York.

Rappaport, A. (2006), Ten Ways to Create Shareholder Value, Harvard Business Review, 84 (9), pp. 66-77.

Rosanas, J. (2008), Beyond Economic Criteria: A Humanistic Approach To Organizational Survival, Journal of Business Ethics, 78 (3), pp. 447-462.

Rosanas, J. (2013), Decision-Making in an Organizational Context: Beyond Economic Criteria, Palgrave Macmillan, Basingstoke, Hampshire.

Simon, H. (1947), Administrative Behavior, New York, The Free Press.

Sitkin, S., and R. Bies (1993), The Legalistic Organization: Definitions, Dimensions, and Dilemmas. Organization Science 4 (3), pp. 345-351. 
Taylor, F. (1911), Principles of Scientific Management, New York, Harper and Brothers.

Von Neumann, J., and 0. Morgenstern (1944), Theory of Games And Economic Behavior, Princeton, Princeton Univ. Press.

Welch, J. (2009), Jack Welch Elaborates: Shareholder Value, Business Week, March 16, http://www.businessweek.com/bwdaily/dnflash/content/mar2009/db20090316_630496.htm, accessed on June 10, 2014.

Williamson, O. E. (1985), The Economic Institutions of Capitalism: Firms, Markets, Relational Contracting, New York and London, The Free Press.

Zeff, S. (1980), Intermediate and Advanced Accounting: The Role of Economic Consequences, The Accounting Review, 55(4), pp. 658-663. 